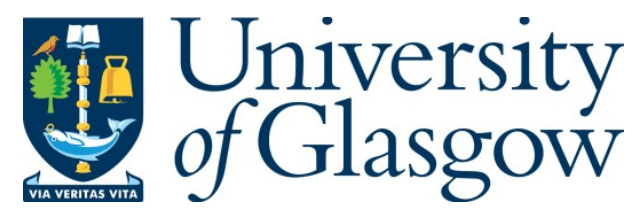

Zhang, N. (2019) Country portfolios under global imbalances. European Economic Review, 119, pp. 302-317.

(doi: 10.1016/j.euroecorev.2019.07.009)

This is the Author Accepted Manuscript.

There may be differences between this version and the published version. You are advised to consult the publisher's version if you wish to cite from it.

https://eprints.gla.ac.uk/193412/

Deposited on: 20 August 2019

Enlighten - Research publications by members of the University of Glasgow http://eprints.gla.ac.uk 


\title{
Country portfolios under global imbalances
}

\author{
Ning Zhang*
}

July 2019

\begin{abstract}
This paper studies the composition of country portfolios under global imbalances. When countries are identical, the optimal portfolio is fully diversified, which reflects the cross-country symmetric self-hedging (Lucas, 1982). Assuming a structural country asymmetry in patience, we construct a model of portfolio choices that features persistent non-zero net foreign assets (NFA). Because the latter opens a gap between GNP and GDP, we found that an asymmetric hedging of net portfolio returns emerges in addition to the otherwise only Lucas' symmetric self-hedging in shaping the gross country portfolios, which implies a short (long) position of the local asset in the debtor (creditor) country. The resulting portfolio is home biased. We calibrate our model to the U.S. and China data over 1999 - 2017 and show that it matches the portfolio data for countries with unbalanced net external positions well.
\end{abstract}

Keywords: Financial globalisation, Global imbalances, International portfolio choices, Asset home bias, External adjustment.

JEL Codes: F32, F41

${ }^{*}$ I thank Alan Sutherland for his guidance and encouragement over the entire process of this research. I am grateful to the Editor Peter Rupert and two anonymous referees for suggestions which have substantially improved the paper. I also thank Gianluca Benigno, Richard Dennis, Tatiana Kirsanova, Campbell Leith, Charles Nolan, Neil Rankin, Ozge Senay and seminar participants at several institutions for helpful comments. Financial support from the ESRC, Grant No. ES/I024174/1, University of St Andrews, and University of Glasgow is gratefully acknowledged. Contact: Adam Smith Business School, University of Glasgow, Glasgow, United Kingdom, G12 8QQ. E-mail: ning.zhang.2@glasgow.ac.uk. 


\section{Introduction}

Financial globalization has been accompanied by global imbalances (Lane and MilesiFerretti, 2007, Gourinchas and Rey, 2013). By the end of 2018, more than 3/4 of countries had a net foreign asset $(N F A)$ position that exceeded $20 \%$ of $G D P$. In the countries considered to be the most important contributors of global imbalances, the $N F A / G D P$ ratio is even higher, over $25 \%$ in China, $-40 \%$ in the U.S. and $60 \%$ in Japan and Germany and it is expected to continue to diverge in the future (IMF, 2017). This implies a correspondingly sizeable and growing gap between the gross external assets and liabilities of these countries. However, in standard country portfolio models, e.g. Devereux and Sutherland (2011) and Heathcote and Perri (2013), countries are assumed to be identical. In this paper, we ask how country portfolios are composed when countries possess unbalanced net external positions.

The presence of non-zero $N F A$ positions implies that the consumption in each country is given by its $G N P$ instead of its GDP. In a world where countries are identical (Lucas, 1982), optimal portfolio positions only consist of a cross-country symmetric $G D P$ hedging. This paper argues that under global imbalances, optimal portfolio positions do not only consist of this $G D P$ hedging but also a hedging associated with the difference between $G N P$ and $G D P$, i.e. the hedging of net portfolio returns, which subsequently influences the international diversification of capital and the external adjustment of the country.

To formalize this idea, we build a model of global imbalances and country portfolios. In our baseline two-country open economy model, first, we borrow a country asymmetry in patience from Buiter (1981) to obtain global imbalances. Second, we allow for trade in two equity-style assets as in symmetric models, e.g. Devereux and Sutherland (2011) and Heathcote and Perri (2013). Third, we assume an overlapping generation (OLG) structure à la Weil (1989) to ensure model stability in this asymmetric environment.

Specifically, we assume that households in the home country are less patient than households in the foreign country (Buiter, 1981, Ferrero et al., 2007), which drives the net capital flows from the foreign to the home country. Interpreted as vehicles of hedging against (relative) national income risks, optimal portfolios are hence composed of portfolio self-hedging and a hedging associated with the return on unbalanced net external positions. As in a symmetric model, the self-hedging entails a cross-country symmetrically short position of local assets. However, because the two countries have an opposite status 
on international payments, the hedging of (current) net portfolio returns works in different ways in the two countries. Taking local asset holdings as an example, this hedging is negative in the home country while positive in the foreign country. To understand this, as a net borrower (lender), the home (foreign) country pays (receives) interest on its net external position. In response to a local income windfall, the interest payment is relatively low. National income and consumption are relatively high (low) while the relative return to the local asset is high. The local asset, therefore, is a bad (good) hedge against the current return to the net portfolio of the home (foreign) country, which delivers a short (long) position of the local asset.

The relative size of this asymmetric hedging has important implications for the pattern of international diversification. We calibrate the model and find that the short (long) position of the local asset implied by this hedging is less (more) sizeable in the home (foreign) country, i.e. the home country prefers to sell less of the home asset to the foreign country while the foreign country holds more local asset domestically. International portfolio allocation must therefore exhibit an equity home bias in the sense that both countries hold more local assets in their own portfolio. This result is relevant when looking at the past few decades of financial globalization in which cross-border financial transactions have grown at a fast rate, while the level of asset home bias has fallen slowly (French and Poterba, 1991, Lewis, 1999, Sercu and Vanpee, 2007, Coeurdacier and Rey, 2012, etc). Through the lens of Lucas' (1982) model, it is natural to conjecture that as the world becomes more open, country portfolios should converge toward a full diversification. This conjecture does, however, rely on the strong assumption of identical countries and is not necessarily true when facing a world of $N F A$ imbalances. According to our result, the optimal portfolios in such a world are in fact characterized by a home-biased allocation, instead of a fully-diversified (or a foreign-biased) allocation.

To explain the observed portfolios in the countries with large unbalanced NFA positions, in an extended model, we incorporate non-financial income and adopt a different asymmetry of financial development (Caballero et al., 2008, 2017). We calibrate the model and find that it produces portfolio positions that are broadly consistent with the U.S. and China data between 1999 - 2017. Through this experiment, we emphasize that, first, the emergence of the hedging of net portfolio returns does not hinge on the particular asymmetry used. Once an asymmetry opens non-zero $N F A$ positions, it simultaneously 
creates the need to hedge against the risk associated with net external income. Second, by introducing the non-financial income, the magnitude of net and gross portfolios is substantially reduced and approaches its empirical counterpart. However, once more, the gap between the gross positions can only be justified in light of the new hedging under global imbalances. Third, the degrees of international portfolio diversification feature a heterogeneity that corroborates the following fact (Coeurdacier and Rey, 2012): In the advanced borrowing country, the asset home bias is less significant than in the emerging lending country, which is because, as before, the hedging of net portfolio returns requires a short (long) position of the local asset in the home (foreign) country and hence tends to dampen (strengthen) the asset home bias there.

Our work is related to a vast literature on global imbalances that uses different types of country asymmetry to account for the persistent non-zero $N F A$ positions between the economically advanced and the emerging/developing countries. The explanations include financial development (Mendoza et al., 2009, Caballero et al., 2008, Angeletos and Panousi, 2011, Coeurdacier et al., 2015), productivity growth (Engel and Rogers, 2006), demographic dynamics (Henriksen, 2005, Attanasio et al., 2006), business cycle volatility (Fogli and Perri, 2015), industrial structure (Jin, 2012), resource relocation (Song et al., 2011), social security system (Eugeni, 2015) and sex imbalance (Wei and Zhang, 2011), etc. While focusing on the determination of the net positions of external assets, this line of literature generally does not touch on the issue of portfolio choices. We fill the gap by taking an integrated approach to the net and gross positions of the country's external wealth.

This paper contributes to another large body of literature on the determination of gross portfolios, most of which aims at reconciling the puzzling asset home bias with various types of hedging motives, e.g. Coeurdacier et al. (2010), Heathcote and Perri (2013) that focus on labour income, Kollmann (2006) on real exchange rate risk, Coeurdacier et al. (2007), Bretscher et al. (2016) on redistributive shocks and Berriel and Bhattarai (2013) on government spending shocks. While this literature considers symmetric models, we analyse the model of asymmetric countries. With the methodological developments such as Tille and Wincoop (2010), Devereux and Sutherland (2011), Evans and Hnatkovska (2012) and Rabitsch et al. (2015), there has also been a growing literature analysing asymmetric portfolio models. Devereux and Sutherland (2009) and Stepanchuk 
and Tsyrennikov (2015) look at the implications of asymmetric market specifications on portfolio choices. Mukherjee (2015) and Steinberg (2018) emphasize the role of differing corporate governance and an evolving global production structure in explaining the lack of portfolio diversification in emerging and developing countries. Our key difference from these papers is that we focus on how, in general, non-zero $N F A$ positions affect the gross portfolio composition via the hedging of net portfolio returns.

Our model also sheds some light on NFA dynamics. In a model that focuses on trade in one asset, e.g. Obstfeld and Rogoff (1996) and most of the literature on global imbalances, a country's external adjustment contains a trade balance effect and an intertemporal terms-of-trade effect (or a valuation effect through net external positions). However, a portfolio valuation effect (on gross positions) is absent because it is not possible to distinguish gross portfolios from net portfolios. In the models with portfolio choices but without global imbalances, e.g. Devereux and Sutherland (2010a), Tille and Wincoop (2010) and Ghironi et al. (2015), however, external adjustment takes through the trade balance effect and the valuation effect (on gross positions). The intertemporal terms-oftrade effect is absent because net portfolios are zero in these symmetric models. Some other studies, e.g. Blanchard et al (2005) and Gourinchas and Rey (2007), accommodate the two aspects but generally use an approach which lacks microeconomic foundations. Embedded with both country asymmetry and portfolio choices, our model captures all three channels of external adjustment and is potentially more suitable for evaluating the implications of related shocks and policies.

We present the baseline model in Section 2. Sections 3 and 4 analyse the portfolio composition under the global imbalances and its implications for international diversification and external adjustment. In Section 5, we calibrate the model, consider its extensions, and contrast the model with data. Section 6 concludes the paper.

\section{The baseline model}

The model is essentially Weil (1989) extended to a two-country world with a country asymmetry in patience (Buiter, 1981) and international portfolios (Devereux and Sutherland, 2011). Specifically, this is a one-good, two-country endowment economy. Except for the asymmetric patience defined below, all other aspects of the two countries are the 
same. We will only describe the home country and use an asterisk to denote foreign variables when necessary. In each country, at time $t=0$, the population is normalized to 1 . It grows at a constant gross rate of $\tilde{n} \equiv 1+n>1$ afterwards and no one dies. A household born at time $v$ maximizes

$$
U_{t}^{v}=E_{t} \sum_{s=t}^{\infty} \beta^{s-t} \log \left(c_{s}^{v}\right)
$$

in the period $t>v$, where $\beta$ and $c_{s}^{v}$ are the discount factor and individual consumption, respectively. Superscripts are used to denote vintage and subscripts for time.

The budget constraint for vintage $v$ household at time $t$ is

$$
\alpha_{1 t+1}^{v}+\alpha_{2 t+1}^{v}=\alpha_{1 t}^{v} r_{1 t}+\alpha_{2 t}^{v} r_{2 t}+y_{t}^{v}-c_{t}^{v}
$$

where $\alpha_{1 t+1}^{v}$ and $\alpha_{2 t+1}^{v}$ denote the household's gross holdings of the two assets, defined below, at the end of time $t . r_{1 t}$ and $r_{2 t}$ are the gross rates of return of assets from time $t-1$ to $t$. Individual endowment and consumption are $y_{t}^{v}$ and $c_{t}^{v}$. Eq.(2) states that the net wealth of a household is given by the portfolio returns plus the net saving.

The maximisation of Eq.(1) subject to Eq.(2) yields the individual Euler equations

$$
\left(c_{t}^{v}\right)^{-1}=\beta E_{t}\left[\left(c_{t+1}^{v}\right)^{-1} r_{j t+1}\right]
$$

for $j=1,2$ and $v=1,2, \ldots, t$. Analogous conditions apply for the foreign country.

By asymmetric patience, we assume $\beta<\beta^{*}$. There are three reasons for this. First, as shown by Buiter (1981), a differing patience leads to unbalanced $N F A$ positions. Second, it simplifies the model solution. We aim at answering our questions in a relatively simple framework à la Lucas (1982). To capture global imbalances in such a framework, the other country asymmetries are either impossible or require additional assumptions and therefore create an increased complexity, while there is no essential change in our key result. As will be clear, what matters here is that the global imbalances, regardless of where they come from, open a gap between GNP and GDP, and therefore create a new hedge motive for households to hold portfolios. As such, third, we are using the asymmetric $\beta$ s as a catch-all for the factors underlying the global imbalances. Ferrero et al. (2007) utilize the same strategy when investigating the implications of current account 


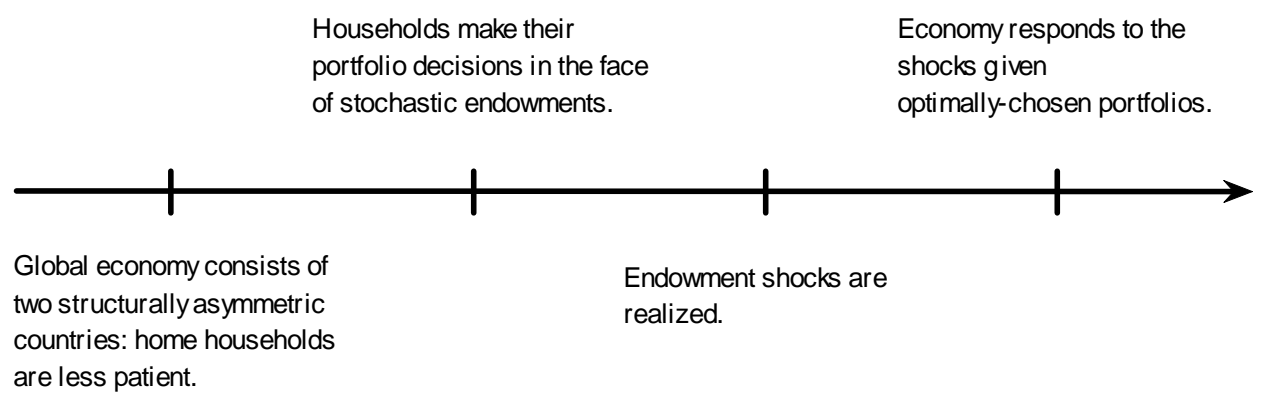

Figure 1: Timeline of the model.

dynamics on optimal monetary policy. Moreover, according to the literature (Bernanke, 2005, Gourinchas and Jeanne, 2013, Gourinchas and Rey, 2013), to explain the global imbalances, the relevant factors also operate through generating an excess saving and a depressed autarky interest rate in the less developed countries. Instead of identifying the source of global imbalances, we focus on their impact on the portfolio composition. We emphasize that, once appearing, the unbalanced $N F A$ s expose households with additional income risks to be hedged by choosing portfolios. We will consider a different asymmetry in Section 5 and show that this mechanism remains, regardless of the type of country asymmetry that is used.

We assume that two assets are traded internationally. They represent claims on the endowment of the issuing country with returns defined by

$$
r_{1 t}=\frac{y_{t}+z_{1 t}}{z_{1 t-1}}, \quad r_{2 t}=\frac{y_{t}^{*}+z_{2 t}}{z_{2 t-1}}
$$

$z_{1 t}$ and $z_{2 t}$ are equity prices. Following Weil (1989), we assume that $y_{t}^{v}=y_{t}, y_{t}^{v *}=y_{t}^{*}$ for all $v$ and $t . y_{t}$ s represent per-capita aggregate incomes that are shocked:

$$
\log \left(y_{t} / y\right)=\mu \log \left(y_{t-1} / y\right)+\varepsilon_{t}, \log \left(y_{t}^{*} / y^{*}\right)=\mu \log \left(y_{t-1}^{*} / y^{*}\right)+\varepsilon_{t}^{*}
$$

In the paper, a per-capita variable without a time subscript denotes its steady-state value. We normalize $y=y^{*}=1$ and assume $0 \leq \mu \leq 1$. $\varepsilon$ and $\varepsilon^{*}$ are zero-mean innovations with $\operatorname{var}(\varepsilon)=\operatorname{var}\left(\varepsilon^{*}\right)=\sigma^{2}$ and $\operatorname{cov}\left(\varepsilon \varepsilon^{*}\right)=0$.

We complete the model description with a timeline of the model, see Figure 1. 


\subsection{Global imbalances in steady state}

As shown below, the international interest rate of the non-stochastic steady state $r_{1}=$ $r_{2}=r$ will lie in between $1 / \beta^{*}$ and $1 / \beta$. Individual consumption is hence tilted downwards in the home country and upwards in the foreign country. There is no steady state for individual variables. However, with the assumed demographic structure, the aggregate per-capita steady state is available and features $N F A$ global imbalances. We describe this steady state below.

Net foreign assets To find the steady-state per-capita NFA, we rewrite Eq. (2) as $w_{t+1}^{v}=w_{t}^{v} r_{2 t}+\alpha_{1 t}^{v} r_{x t}+y_{t}^{v}-c_{t}^{v}$ by defining $w_{t+1}^{v}=\alpha_{1 t+1}^{v}+\alpha_{2 t+1}^{v}$ as household net wealth and $r_{x t}=r_{1 t}-r_{2 t}$ as the excess return of asset 1 over asset 2. Using this budget constraint and Euler equations, we obtain the individual consumption function

$$
c_{t}^{v}=(1-\beta)\left[r w_{t}^{v}+\sum_{i=0}^{\infty} \frac{1}{r^{i}} y_{t+i}\right]
$$

Following Weil (1989), we assume that households are born with no wealth. Therefore,

$$
c_{t}^{n} \equiv c_{t}^{t}=(1-\beta) \sum_{i=0}^{\infty} \frac{1}{r^{i}} y_{t+i}
$$

where we introduce $c_{t}^{n}$ with a superscript $n$ to denote the consumption of new-borns.

We aggregate the individual budget constraint and the consumption function to yield $w_{t+1}=\frac{r \beta}{\tilde{n}} w_{t}+\frac{r \beta-1}{\tilde{n}(r-1)} y_{t}$. Assuming a stability condition $\tau \equiv r \beta / \tilde{n}<1$, we obtain

$$
w=\alpha_{1}+\alpha_{2}=\frac{r \beta-1}{(\tilde{n}-r \beta)(r-1)}<0
$$

Since $(r \beta-1)<0$, the home country will be in a position of net debt. In contrast, the foreign country will be in a position of net credit, $w^{*}=\frac{r \beta^{*}-1}{\left(\tilde{n}-r \beta^{*}\right)(r-1)}>0$. These results confirm the intuition that the impatient country consumes by borrowing while the patient country saves by lending.

International interest rate Table 1 shows the net holdings of assets in the two countries. Asset market clearing requires $z_{1}+\alpha_{1}+\alpha_{1}^{*}=z_{1}$ and $w-\alpha_{1}+z_{2}+w^{*}-\alpha_{1}^{*}=z_{2}$, 
Table 1: Net asset holdings across countries

\begin{tabular}{lll}
\hline \hline & Home holdings & Foreign holdings \\
\cline { 2 - 3 } Asset 1-Home equity & $\alpha_{1}+z_{1}$ & $\alpha_{1}^{*}$ \\
Asset 2-Foreign equity & $\alpha_{2}=w-\alpha_{1}$ & $\alpha_{2}^{*}+z_{2}=w^{*}-\alpha_{1}^{*}+z_{2}$ \\
\hline
\end{tabular}

which is equivalent to $\alpha_{1}^{*}=-\alpha_{1}$ and $w^{*}=-w$. The first equation implies that in solving portfolio allocations, we only need to solve for $\alpha_{1}$. The other three $\alpha$ s are linked to $\alpha_{1}$ through $w$ and $z$. Denoting $\alpha \equiv \alpha_{1}$, we focus on solving for $\alpha$ in Section 3 . The second equation states that the positions of home deficit and foreign surplus should be equal, which determines $r$

$$
r=\frac{(1+\tilde{n})\left(\beta+\beta^{*}\right)-\sqrt{(1+\tilde{n})^{2}\left(\beta+\beta^{*}\right)^{2}-16 \tilde{n} \beta \beta^{*}}}{4 \beta \beta^{*}}
$$

It is easy to verify our previous assertion that $1 / \beta^{*}<r<1 / \beta$. In addition, $r$ is decreasing in the $\beta$ s and increasing in $\tilde{n}$.

Consumption Eq.(2) implies $c=1+(r-\tilde{n}) w$. We assume $r>\tilde{n}$ and focus on the case of a dynamically efficient steady state. In this case, we have $w<0$ and $c<1$ for the home country while we have $w^{*}>0$ and $c^{*}>1$ for the foreign country. That is, the impatient country consumes less than its average income, which reflects the fact that the country runs a trade deficit and some domestic resources are used to service international interest payments. In contrast, with a relatively higher $\beta$, the foreign country as a whole consumes more than its average income because per-capita GNP is higher than GDP and there is a positive international interest income.

For later use, we derive a relation between $c$ and $c^{n}, c=\frac{n}{(\tilde{n}-r \beta)} c^{n}$. Because in each period, the new-born cohort only accounts for $n / \tilde{n}$ of the total population, the steadystate fraction of consumption that is due to new-borns is given by $\frac{n}{\tilde{n}} \frac{(\tilde{n}-r \beta)}{n} \equiv 1-\tau$. The remainder, $\tau$, represents the steady-state fraction of consumption that is due to old generations. This provides an interpretation of the stability condition previously imposed, i.e. $\tau<1$ for $w_{t+1}=\tau w_{t}+\frac{r \beta-1}{\tilde{n}(r-1)} y_{t}$ to converge to (8). This condition does actually just require that the consumption share of the old and that of the new-born are both positive, which is mild and economically sensible. 


\section{Optimal portfolios under global imbalances}

The growing literature on portfolio computation provides the method for solving the model. Previously, portfolio choices in macroeconomic models have not been easy to compute. This is because, when applying the standard first-order log-linearization technique, we lose the higher-order terms that capture the risk characteristics of assets, from which portfolios are indeterminate. This literature, e.g. Tille and Wincoop (2010) and Devereux and Sutherland (2011), therefore suggests approximating the portfolio equations to a higher-order accuracy in order to capture the assets' risk characteristics. Following the literature, we approximate the model up to second-order accuracy around the above steady state. With unbalanced NFAs and population growth, the current model produces income risks and optimal asset holdings that are different from a symmetric model. We analyse them in this section.

Throughout the paper, a hat variable denotes its log-deviation from the steady state, e.g. $\quad \hat{c}_{t}=\log \left(\frac{c t}{c}\right)$ and $\hat{r}_{t}=\log \left(\frac{r_{t}}{r}\right)$, except for $\hat{w}$. In conventional symmetric models, $w=0$ so $\hat{w}$ is usually defined as a deviation of $w_{t}$ relative to steady-state GDP, i.e. $\log w_{t}-\log y$. We follow this to make the comparison between the results in our paper and the existing literature more convenient.

The optimal condition for $\alpha$ is $(\text { Appendix } C)^{1}$

$$
E_{t-1}\left[\hat{c}_{t}^{D} \hat{r}_{x t}\right]=0
$$

where $\hat{c}_{t}^{D} \equiv\left[\frac{1}{\tau}\left(\hat{c}_{t}-(1-\tau) \hat{c}_{t}^{n}\right)-\frac{1}{\tau^{*}}\left(\hat{c}_{t}^{*}-\left(1-\tau^{*}\right) \hat{c}_{t}^{n *}\right)\right]$ can be referred to as the crosscountry portfolio-relevant consumption differential. According to this condition, $\alpha$ is determined by first-order behaviours of the excess return $\hat{r}_{x t}$ and $\hat{c}_{t}^{D} . \hat{r}_{x t}$ has the same form as in a standard symmetric model, $\hat{r}_{x t}=\frac{(r-1)}{(r-\mu)}\left(\varepsilon_{t}-\varepsilon_{t}^{*}\right)$. For $\hat{c}_{t}^{D}$, apart from $\tau, \tau^{*} \neq 1$, it differs from that of a symmetric model, i.e. $\left(\hat{c}_{t}-\hat{c}_{t}^{*}\right)$ (Appendix $A$ ), by subtracting the relative consumption of new-borns. This is because we assumed that new-borns are born with zero assets and do not make any portfolio choices.

Eq. (10) also tells us how to interpret $\alpha$. Given the concave utility function, it is always desirable for households to ensure a relatively smooth pattern of consumption across uncertain states. In the model, this is achieved by households investing in assets

\footnotetext{
${ }^{1}$ Throughout the paper, appendix refers to the Online Appendix to the paper.
} 
with a relatively high return while their income and consumption are relatively low. $\alpha$ can be viewed as a hedging of the relative national income risks underlying $\hat{c}_{t}^{D}$.

Appendix $D$ shows that

$$
\begin{aligned}
\hat{c}_{t}^{D}= & \frac{r}{r-\mu \tilde{n}}\left[\frac{1-\beta}{c \tau} \hat{y}_{t}-\frac{1-\beta^{*}}{c^{*} \tau^{*}} \hat{y}_{t}^{*}\right]-\frac{\tilde{n}}{r-\mu \tilde{n}}\left[\frac{(1-\tau)}{\tau} \hat{c}_{t+1}^{n}-\frac{\left(1-\tau^{*}\right)}{\tau^{*}} \hat{c}_{t+1}^{n *}\right] \\
& +r \phi w \hat{r}_{2 t}+\frac{\tilde{n}}{r} r \phi w \Sigma_{t+1}^{r n}-\left[\frac{(1-\tau)}{\tau} \hat{c}_{t}^{n}-\frac{\left(1-\tau^{*}\right)}{\tau^{*}} \hat{c}_{t}^{n *}\right]+r \phi \alpha \hat{r}_{x t}
\end{aligned}
$$

where $\phi \equiv \frac{(1-\beta)}{c \tau}+\frac{\left(1-\beta^{*}\right)}{c^{*} \tau^{*}}$ and $\sum_{t+1}^{r n} \equiv \sum_{i=0}^{\infty}\left(\frac{\tilde{n}}{r}\right)^{i} \hat{r}_{t+1+i}$. Except for $r \phi \alpha \hat{r}_{x t}, \hat{c}_{t}^{D}$ consists of the following risk factors:

1. The (relative) endowment effect $\hat{c}_{t}^{D}[1]$, i.e. the first two terms on the right-hand-side $(R H S)$. The first term, $\frac{r}{r-\mu \tilde{n}}\left[\frac{1-\beta}{c \tau} \hat{y}_{t}-\frac{1-\beta^{*}}{c^{*} \tau^{*}} \hat{y}_{t}^{*}\right]$, denotes the relative endowment movement belonging to both the existing and yet-to-be-born generations. The second term, $\frac{\tilde{n}}{(r-\mu \tilde{n})}\left[\frac{(1-\tau)}{\tau} \hat{c}_{t+1}^{n}-\frac{\left(1-\tau^{*}\right)}{\tau^{*}} \hat{c}_{t+1}^{n *}\right]$, only denotes those due to the yet-to-be-born generations. The difference between them can be viewed as a relative GDP effect, the only term that is present in a symmetric model.

2. The (relative) current and future net-portfolio-return effects $\hat{c}_{t}^{D}[2]=r \phi w \hat{r}_{2 t}$ and $\hat{c}_{t}^{D}[3]=\frac{\tilde{n}}{r} r \phi w \sum_{t+1}^{r n}$. They emerge because $w \neq 0$, which implies non-zero international payments. These and the above $\hat{c}_{t}^{D}[1]$ taken together can be viewed as a relative GNP effect.

3. The (relative) new-borns' consumption effect $\hat{c}_{t}^{D}[4]=-\left[\frac{(1-\tau)}{\tau} \hat{c}_{t}^{n}-\frac{\left(1-\tau^{*}\right)}{\tau^{*}} \hat{c}_{t}^{n *}\right]$. It emerges because, as mentioned, only the old cohorts' decisions matter in order to determine the optimal portfolio. It disappears in a standard symmetric model because the $O L G$ structure is unnecessary and absent there.

Making use of Eqs. (10) and (11), we obtain

$$
\alpha=\underbrace{-\frac{\operatorname{cov}\left(\Delta y_{t}, \hat{r}_{x t}\right)}{\operatorname{var}\left(\hat{r}_{x t}\right)}-w \frac{\operatorname{cov}\left(\hat{r}_{2 t}, \hat{r}_{x t}\right)}{\operatorname{var}\left(\hat{r}_{x t}\right)}-\frac{\tilde{n} w}{r} \frac{\operatorname{cov}\left(\sum_{t+1}^{r n}, \hat{r}_{x t}\right)}{\operatorname{var}\left(\hat{r}_{x t}\right)}}_{\alpha[1]<0}+\underbrace{\frac{\operatorname{cov}\left(\Delta c_{t}^{n}, \hat{r}_{x t}\right)}{\operatorname{var}\left(\hat{r}_{x t}\right)}}_{\alpha[2]<0}
$$

where $\Delta y_{t} \equiv \frac{1}{r \phi} \hat{c}_{t}^{D}[1]$ and $\Delta c_{t}^{n} \equiv \frac{1}{r \phi} \hat{c}_{t}^{D}[4]$ are relative income and relative new-borns' consumption. We explain $\alpha$ 's components in turn. 
Diversification term or self-hedging term $\alpha[1]=-\frac{1}{2(r-1)} \frac{(r-\mu)}{(r-\mu \tilde{n})}+\frac{1}{2 r \phi} \frac{\mu \tilde{n}}{r-\mu \tilde{n}}\left[\frac{1-\tau}{\tau}+\frac{1-\tau^{*}}{\tau^{*}}\right]$. It reflects the households' motive to hedge against $\hat{c}_{t}^{D}[1]$. Imposing $\tilde{n}=1, \tau=\tau^{*}=1$, it collapses into the case of a symmetric model, $\alpha=-\frac{1}{2(r-1)}=-\frac{z}{2}$, i.e. a full diversification of portfolios (Lucas, 1982, Devereux and Sutherland, 2011, Coeurdacier and Rey, 2013, etc). Appendix $E$ proves that the self-hedging in the baseline model is identical to that of a symmetric model, i.e.

$$
\alpha[1]=-\frac{1}{2(r-1)}<0 .
$$

$\alpha$ contains the following additional components due to the presence of country asymmetry and population growth in our model.

\section{Hedging the current net portfolio returns}

$$
\alpha[2]=-\frac{(r-\mu)\left(\zeta_{r 2 e 1}-\zeta_{r 2 e 2}\right) w}{2(r-1)}<0
$$

where $\zeta_{r 2 e 1}$ and $\zeta_{r 2 e 2}$ are responses of $\hat{r}_{2 t}$ to home and foreign shocks $\left\{\varepsilon_{t}, \varepsilon_{t}^{*}\right\}$. It reflects households' motive to hedge against $\hat{c}_{t}^{D}[2]$. In symmetric models where $w=0, \alpha[2]=0$.

The sign of $\alpha[2]$ depends on the relative magnitude of $\zeta_{r 2 e 1}$ and $\zeta_{r 2 e 2}$. According to the asset pricing relations, a positive shock in either country increases the rate of return for both assets. For the abroad asset, the increase in the return arises because of lower expected future interest rates and thus higher capital gains today. For the local asset, the increase arises because of not only higher capital gains but also a higher dividend payment. Thus, $\zeta_{r 2 e 1}$ and $\zeta_{r 2 e 2}$ are both positive and $\zeta_{r 2 e 1}<\zeta_{r 2 e 2}$.

This hedging is negative. Note that the home country is a debtor country and has to pay interest on $w$. Home and foreign (positive) shocks both boost the current interest rate and thus also the interest payment to the foreign country. Since $\zeta_{r 2 e 1}<\zeta_{r 2 e 2}$, the increase in the interest payment is smaller in response to the home shock. That is, when home consumption is high, the excess return is also high, so asset 1 is a bad hedge against the risk of this income stream. The home country therefore chooses to short asset 1.

\section{Hedging the future net portfolio returns}

$$
\alpha[3]=-\frac{(r-\mu)\left(\zeta_{s r e 1}-\zeta_{s r e 2}\right)}{2(r-1)} \frac{\tilde{n} w}{r}
$$


where $\zeta_{s r e 1}$ and $\zeta_{s r e 2}$ are the responses of $\Sigma_{t+1}^{r n}$ to home and foreign shocks $\left\{\varepsilon_{t}, \varepsilon_{t}^{*}\right\}$. Since, as a supply shock, the endowment increase in either country tends to reduce the expected future interest rates, $\zeta_{s r e 1}$ and $\zeta_{s r e 2}$ are both negative.

The sign of $\alpha[3]$ depends on the relative magnitude of $\zeta_{s r e 1}$ and $\zeta_{s r e 2}$. In other words, it depends on the answer to the following question: under global imbalances, in which country does an income rise depress the expected future interest rate more efficiently? If the foreign income shock is more powerful in this regard, then $\alpha[3]$ is positive. To understand this, note that the home country has to pay interest on $w$ not only in the current period but also in subsequent periods after shocks. Home and foreign (positive) shocks both depress the expected future interest rates. When $\zeta_{\text {sre } 1}>\zeta_{\text {sre } 2}$, the home shock induces a relatively moderate decrease in interest payments (so consumption is relatively low) while the excess return on asset 1 is relatively high. Thus, asset 1 is a good hedge against the future net portfolio return risk in terms of smoothing relative consumption. The home country therefore chooses a long position on asset 1 . Otherwise, if $\zeta_{\text {sre } 1}<\zeta_{\text {sre } 2}$, asset 1 would be shorted.

\section{Adjustment term due to the demographic structure}

$$
\alpha[4]=\frac{1}{2 r \phi}\left[\frac{1-\tau}{\tau}+\frac{1-\tau^{*}}{\tau^{*}}\right]>0
$$

Because we assumed that it is only the decisions of the old population that matter, the above term corresponds to a deduction of the consumption of yet-unborns from $\hat{c}_{t}^{D}$. Note that the deduction is more responsive to the home shock than to the foreign shock, $\frac{(1-\tau)}{\tau}>\frac{\left(1-\tau^{*}\right)}{\tau^{*}}$. When, for instance, there is a positive shock to the home country, because the deduction of new-borns' consumption is relatively high, $\hat{c}_{t}^{D}$ is relatively low while $\hat{r}_{x t}$ is relatively high. So asset 1 is, in a sense, a good hedge against this part of risk, which explains a positive sign of $\alpha[4]$.

\section{Portfolio diversification and external adjustment}

With the above additional hedging terms, the implied portfolio is expected to differ from the full diversification of Lucas (1982). In particular, we wonder if it is biased toward the 
local or abroad asset. Since $z_{1}=z_{2}$, we only need a condition concerning one of the two countries. For the case of home bias, this is $\left(z_{1}+\alpha_{1}\right) /\left(z_{1}+\alpha_{1}-\alpha_{2}^{*}\right)>1 / 2$, i.e. the share of asset 1 in the home country's portfolio exceeds that in the world portfolio. Appendix $F$ shows that, similar to $\alpha$, the foreign gross holding of foreign asset $\alpha_{2}^{*} \equiv \alpha^{*}$ also comprises the same hedging terms as in Section 3. However, in $\alpha^{*}$, first, the hedging of current net portfolio returns $\alpha^{*}[2]=-w^{*} \frac{\operatorname{cov}\left(\hat{r}_{1 t}, \hat{r}_{x t}^{*}\right)}{\operatorname{var}\left(\hat{r}_{x t}^{*}\right)}>0$ as opposed to $\alpha[2]=-w \frac{\operatorname{cov}\left(\hat{r}_{2 t}, \hat{r}_{x t}\right)}{\operatorname{var}\left(\hat{r}_{x t}\right)}<0$. Second, all other hedging terms are the same as in $\alpha$. Therefore, whether the portfolio allocation is home-biased or not depends on the relative size of $\alpha[2]$ and $\alpha^{*}[2]$ that is controlled by the above covariances. An equity home bias emerges if $\operatorname{cov}\left(\hat{r}_{1 t}, \hat{r}_{x t}^{*}\right)<$ $\operatorname{cov}\left(\hat{r}_{2 t}, \hat{r}_{x t}\right)<0$ where $\hat{r}_{x t}^{*} \equiv-\hat{r}_{x t}=\hat{r}_{2 t}-\hat{r}_{1 t}$. To understand, when this condition holds, the hedging of the current net portfolio returns implies a relatively smaller short position of the home asset in the home portfolio, while it implies a relatively larger long position of the foreign asset in the foreign portfolio. All other hedging terms and asset supplies being equal, this means that both countries hold relatively more of their local asset in their country portfolios.

Both $w$ and $\alpha$ being determined, we combine the two countries' budget constraints to obtain

$$
\hat{w}_{t+1}-\hat{w}_{t}=\frac{r-\tilde{n}}{\tilde{n}} \hat{w}_{t}+\underbrace{\frac{r w}{\tilde{n}} \hat{r}_{2 t}}_{T T_{t}}+\underbrace{\frac{r \alpha}{\tilde{n}} \hat{r}_{x t}}_{V A L_{t}}+\underbrace{\frac{1}{2 \tilde{n}}\left[\hat{y}_{t}-\hat{y}_{t}^{*}-\left(c \hat{c}_{t}-c^{*} \hat{c}_{t}^{*}\right)\right]}_{T B_{t}}
$$

Besides the traditional trade channel $T B$, an intertemporal terms-of-trade effect on net portfolios $(T T)$ and a valuation effect on gross portfolios $(V A L)$ are generated at the same time. The two additional effects, $T T$ and $V A L$, are both portfolio "valuation effects" and are captured empirically in the literature (Gourinchas and Rey, 2007). The existing theoretical models, however, fail to capture the two effects at the same time. The $V A L$ effect is missing from the traditional single-bond literature because $\alpha$ is absent there, e.g. Bhagwatti (1958) and Obstfeld and Rogoff (1996). When they refer to the valuation effect, it is actually only the $T T$ effect that exists. On the other hand, the TT effect is missing from recent symmetric models of country portfolios because $w=0$ there, e.g. Devereux and Sutherland (2010a), Tille and Wincoop (2010) and Ghironi et al. (2015). When they refer to valuation effects, it is actually only the $V A L$ effect that exists. 
Iterating forward Eq. (13), we obtain the intertemporal external constraint

$$
\hat{w}_{t}=-\sum_{j=0}^{+\infty}\left[\frac{\tilde{n}}{r}\right]^{j+1}\left\{T T_{t+j}+V A L_{t+j}+T B_{t+j}\right\} .
$$

This equation can be read in parallel with the similar equations in the literature, for example Eq. (9) of Gourinchas and Rey (2007) and Eq. (3) of Blanchard et al. (2005). Note that because the net and gross portfolio positions are endogenously determined in this model, the terms of trade and valuation effects generated here are fully endogenous and micro-founded in contrast to these two other papers.

\section{Model calibration and extension}

\subsection{Calibrating the baseline model}

There are only four parameters in the baseline model, two $\beta \mathrm{s}, n$ and $\mu$. Taking one year as the frequency, we set $\beta$ at 0.96 as is commonly used in the literature. As a benchmark, we set $\beta^{*}$ one percentage higher and $n$ at $0.01,{ }^{2}$ under which the stability and dynamic efficiency conditions, i.e. $\tau, \tau^{*}<1$ and $r>\tilde{n}$, hold. These are combined to imply an autarky annual interest rate of $4 \%$ in the home country while it is $1 \%$ lower in the foreign country. $\mu$ is set to be the medium estimate by Smets and Wouters (2007).

Column (3) of Table 2 lists all parameter values and the resulting steady state. Given the parameterization, $r$ is computed to be around $3.4 \%$. The magnitudes of the NFA position and the asset supplies are very large. A one percent difference between $\beta$ s results in a $w$ of around 12.5 times GDP. The asset stock is around 30 times GDP. Both are too large from an empirical point of view. This is because, like Lucas (1982), we assume that all incomes are capitalizable. We stick to this specification here to make it easy to compare the portfolio models with and without global imbalances that are both based on the Lucas' (1982) full-diversification benchmark. We will relax this assumption in the next section.

\footnotetext{
${ }^{2}$ Cavallo and Ghironi (2002) and Ghironi (2006) find that the average rate of quarterly population growth for the U.S. between 1973:1 and 2000:3 has been 0.0025.
} 


\begin{tabular}{|c|c|c|c|c|c|}
\hline Variable & Symmetric model & \multicolumn{4}{|c|}{ This asymmetric model } \\
\hline Home discount factor $\beta$ & 0.96 & \multicolumn{4}{|c|}{0.96} \\
\hline Shock persistence $\mu$ & 0.95 & \multicolumn{4}{|c|}{0.95} \\
\hline \multirow[t]{2}{*}{ Population growth rate $n$} & - & & & & \\
\hline & (1) & $(2)$ & $(3)$ & $(4)$ & (5) \\
\hline Foreign discount factor $\beta^{*}$ & 0.96 & 0.965 & 0.97 & 0.975 & 0.98 \\
\hline Home Euler equation parameter $\tau$ & - & 0.987 & 0.983 & 0.978 & 0.974 \\
\hline Foreign Euler equation parameter $\tau^{*}$ & - & 0.992 & 0.993 & 0.994 & 0.994 \\
\hline Home net foreign asset $w$ & 0 & -6.37 & -12.47 & -18.59 & -25.67 \\
\hline International interest rate $r$ & 1.042 & 1.038 & 1.034 & 1.029 & 1.024 \\
\hline Asset stock $z_{1}, z_{2}$ & 24 & 26.108 & 29.414 & 34.184 & 41.10 \\
\hline Home consumption $c$ & 1 & 0.82 & 0.70 & 0.64 & 0.63 \\
\hline Foreign consumption $c^{*}$ & 1 & 1.18 & 1.30 & 1.35 & 1.37 \\
\hline Optimal portfolio holding $\alpha$ & -12 & -16.106 & -20.773 & -26.146 & -33.012 \\
\hline - Self-hedging $\alpha[1]$ & -12 & -13.054 & -14.707 & -17.092 & -20.550 \\
\hline - Hedging current NFA returns $\alpha[2]$ & 0 & -3.183 & -6.221 & -9.247 & -12.720 \\
\hline - Hedging future NFA returns $\alpha[3]$ & 0 & 0.002 & 0.009 & 0.025 & 0.054 \\
\hline - Demographic adjustment term $\alpha[4]$ & 0 & 0.129 & 0.146 & 0.169 & 0.204 \\
\hline $\operatorname{cov}\left(\hat{r}_{2 t}, \hat{r}_{x t}\right)$ & -0.2066 & -0.1880 & -0.1634 & -0.1356 & -0.1062 \\
\hline $\operatorname{cov}\left(\hat{r}_{1 t}, \hat{r}_{x t}^{*}\right)$ & -0.2066 & -0.1883 & -0.1642 & -0.1369 & -0.1081 \\
\hline $\operatorname{var}\left(\hat{r}_{x t}\right)$ & 0.4132 & 0.3763 & 0.3276 & 0.2725 & 0.2143 \\
\hline External adjustment - Trade effect & 0.5 & 0.575 & 0.625 & 0.645 & 0.637 \\
\hline - Intertemporal $T T$ effect & 0 & -1.653 & -3.349 & -5.172 & -7.378 \\
\hline - Gross portfolio $V A L$ effect & -5.6818 & -7.182 & -8.607 & -9.835 & -10.959 \\
\hline$\left(z_{1}+\alpha\right) /\left(z_{1}+\alpha-\alpha^{*}\right)$ & 0.5 & 0.5068 & 0.5101 & 0.5154 & 0.5242 \\
\hline
\end{tabular}

Table 2: Simulation of the baseline model (y and $\mathrm{y}^{*}$ are normalized at 1 ) 


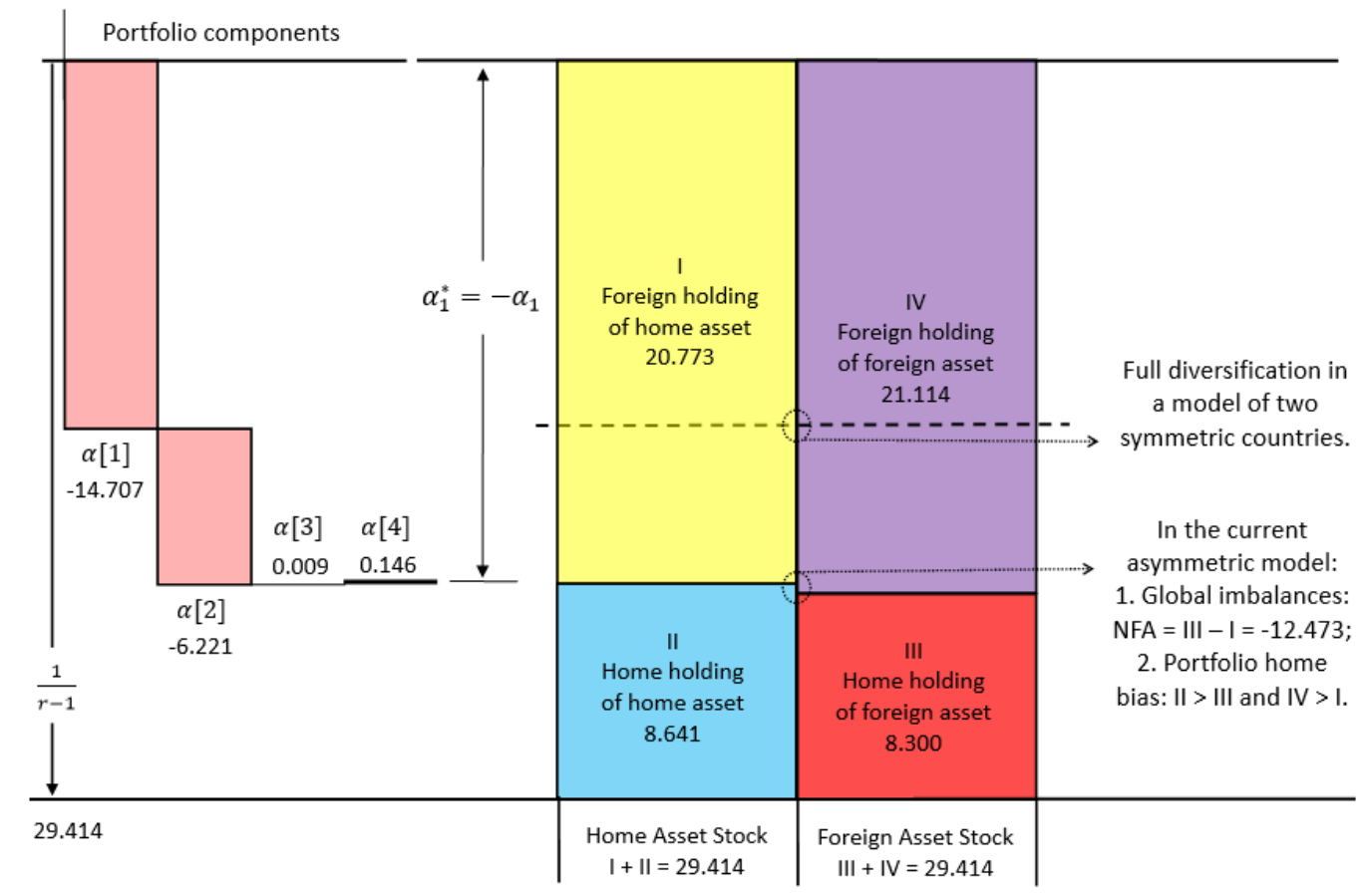

Figure 2: Steady-state international portfolios under global imbalances.
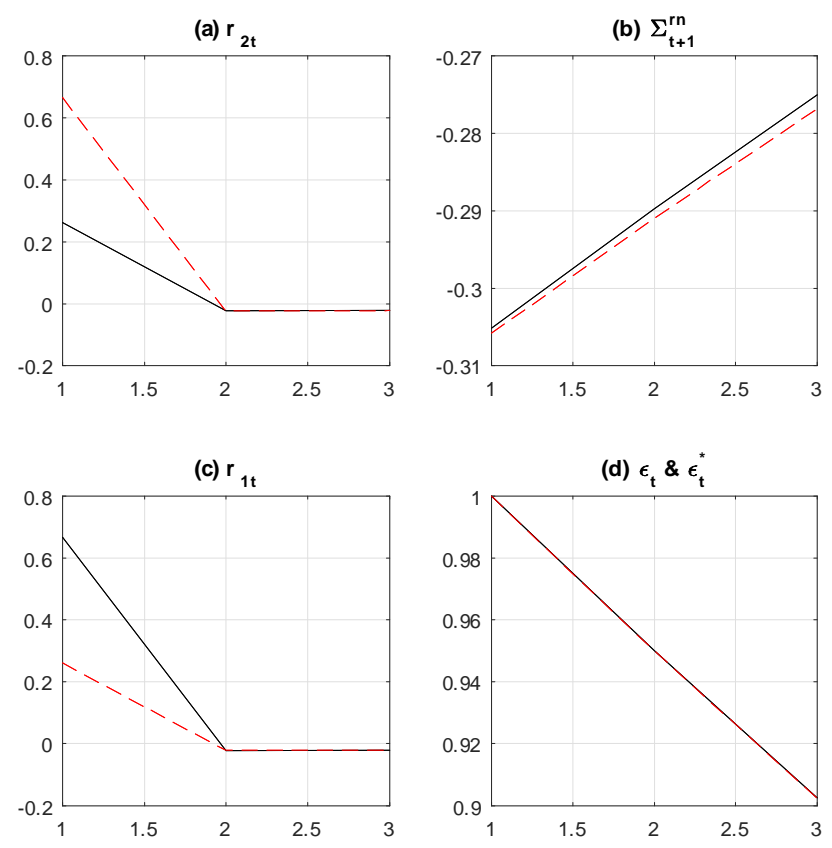

Figure 3: Response of $\hat{r}_{2 t}, \Sigma_{t+1}^{r n}$ and $\hat{r}_{1 t}$ to a positive home (solid line) shock $\varepsilon$ and a foreign (dashed line) shock $\varepsilon^{*}$. By panel $(a), \zeta_{r 2 e 1}<\zeta_{r 2 e 2}$. By panel $(b), \zeta_{s e 1}>\zeta_{s e 2}$. 
International portfolios The $\alpha$ is computed to be -20.773 . Figure 2 plots its components and the implied portfolio allocation. The left half of the figure shows $\alpha[1]$ to $\alpha[4]$ with 4 bars. To represent their signs, negative components are accumulated from the top line (whose height denotes $z_{1}=z_{2}$ ) downwards, while positive components are accumulated the other way around. The height of the bars corresponds to their sizes.

For the first and longest bar to the left $\alpha[1]$, because home GDP always moves in the same direction as the home asset return, the home asset is a bad hedge against the risk. It is shorted by home households. The second bar represents $\alpha[2]$. Since $\operatorname{Cov}\left(\hat{r}_{2 t}, \hat{r}_{x t}\right)<0$, or from Figure $3(a), r_{2 t}$ always increases more in response to the foreign shock than to the home shock $0<\zeta_{r 2 e 1}<\zeta_{r 2 e 2}$, the home asset is a bad hedge against the associated income. Home households further short the home asset. As for $\alpha$ [3], Figure $3(b)$ shows that $\Sigma_{t+1}^{r n}$ is more responsive to the shock in the foreign country $0>\zeta_{\text {sre } 1}>\zeta_{s r e 2}$. This leads to a positive $\alpha[3]$. Finally, $\alpha[4]$ is always positive as expected.

In terms of size, because $\alpha[1]$ is linked to the risk associated with the relative $G D P$ effect, the most important source of risk, the diversification term is the largest component, $\alpha[1]=-14.707$. As proved, it equals $z / 2$. Under global imbalances, $\alpha[2]$ is linked to the risk associated with the income difference between GNP and GDP, which should be secondary as compared to GDP risks. The hedging is thus less substantial. However, with a very large $w$ here, the hedging is still considerable, $\alpha[2]=-6.221$. Lastly, $\alpha[3]$ and $\alpha[4]$ are found to be small. By selecting a low $n, \alpha[4]$ is purposefully kept small. $\alpha[3]$ is small because asset prices have the opportunity to adjust such that the expected future asset returns respond to the two shocks with not much difference (Figure $3(b)$ ).

The right-hand half of Figure 2 shows the portfolio diversification. There are two wide columns representing $z_{1}=z_{2}$. The values are divided by two solid lines so that there are four cells representing portfolio holdings in our model, i.e. the foreign holding of the home asset of 20.773, the home holding of the home asset of 8.641, the home holding of the foreign asset of 8.300, and the foreign holding of the foreign asset of 21.114, respectively. Another dashed line in the middle of the two columns divides them into four cells of the same area, corresponding to the Lucas' (1982) fully diversified allocation.

The current model deviates from the Lucas' (1982) symmetric case in two ways. First, the NFAs are non-zero. The two solid lines move from the dashed line downwards to create an area that represents the presence of global imbalances. Second, the net portfolio 
allocations under global imbalances exhibit an asset home bias. Note that the left solid line is higher than the right one. That is, the home (foreign) holding of the home (foreign) asset is larger than the home (foreign) holding of the foreign (home) asset, even though the two assets are equally supplied in the world. As analysed, the asymmetry in the model biases the portfolio of the two countries towards local assets through the heterogeneous hedging of net portfolio returns across countries. ${ }^{3}$

Risk-sharing and external adjustment Figure 4 plots the economy's response to a home shock in the cases with (solid line) and without (dashed line) holdings of international portfolios. By 'without portfolio', we mean that the condition of $\alpha=0$ is imposed. We show this hypothetical case and compare it to the case with portfolios in order to highlight the role of the presence of portfolio choices in giving rise to the $V A L$ effect. ${ }^{4}$ Panels $(a)$ to $(h)$ depict responses of $\hat{c}^{D}, \hat{w}$, home and foreign consumption, the trade balance effect, the terms of trade effect, the valuation effect, and the income shock $\varepsilon$.

In the case without portfolio holdings, most of the effect of a higher $\varepsilon$ will be on home consumption because the shock mainly works through the increased GDP (see the high dashed line in $(c)$ compared to the low dashed line in $(d)$ ). The gap between home and foreign consumption is thus very large at around 0.73, as shown in $(a)$. However, if optimal portfolios are in place, the rise in the home endowment affects consumption not only by affecting $G D P$, but also by affecting portfolio returns. The attendant negative $T T$ and $V A L$ effects imply a large wealth transfer from the home to the foreign country. Net external wealth, $\hat{w}$, is lower than in the case without portfolios (see $(b)$ ). Home consumption is depressed (to the low solid line in $(c)$ at the level of around 0.5) at the same time as foreign consumption is elevated (to the high solid line in $(d)$ also at the level of around 0.5). The consumption differential across countries is thus narrowed down substantially, indicating a significantly improved level of risk-sharing across countries.

To better see the roles of trade and valuation channels in affecting a country's external adjustment, we plot each component of $\hat{w}$ in the remaining panels of Figure 4. (e) shows that the positive home shock raises the trade balance, which is due to the fact that when GDP increases, consumption increases but less than one for one. Without portfolio

\footnotetext{
${ }^{3}$ These results are robust to a series of checks, see Appendix $I$.

${ }^{4}$ In Appendix $G$, we instead compare $\hat{w}$ 's dynamics to that without country asymmetry to highlight the role of non-zero $w$ s in generating the $T T$ effect.
} 
(a) $\hat{c}_{t}^{D}$

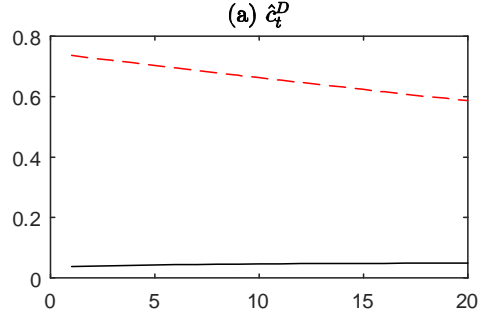

(c) $\hat{c}_{t}$

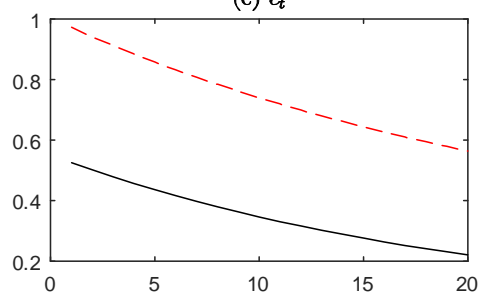

(e) $T B_{t}$

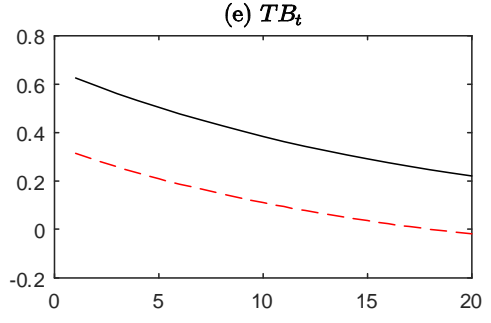

(g) $V A L_{t}$

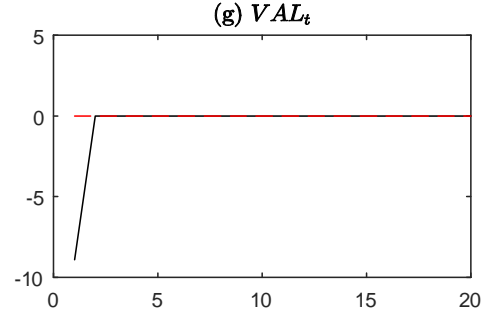

(b) $\hat{w}_{t}$

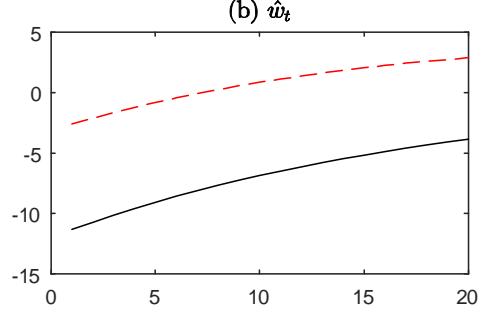

(d) $\hat{c}_{t}^{*}$

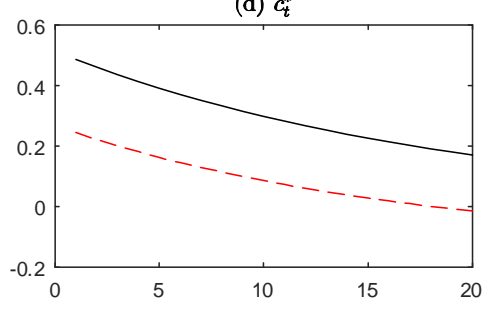

(f) $T T_{t}$

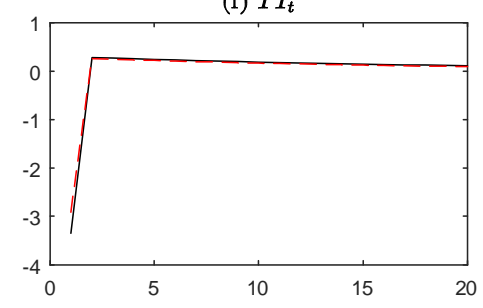

(h) $\hat{y}_{t}$

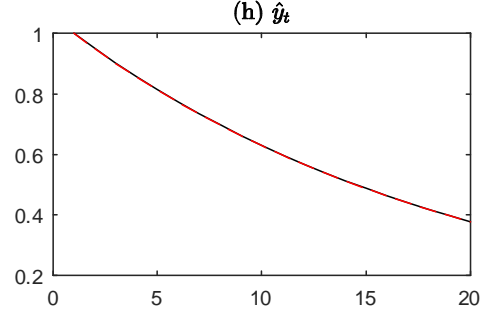

Figure 4: IRFs to home shock in a model with (solid line) and without (dashed line) gross portfolio choices 
choices, this is represented by the dashed line in $(e)$. If countries hold optimal portfolios, the increase in home consumption will be lesser because there will be a negative $V A L$ effect (shown below) which reduces wealth. The trade balance can therefore be higher (a higher solid line than dashed line in $(e))$. For $(f)$, first look at the dashed line. Because $\hat{r}_{2}$ is immediately driven up after the shock, the TT effect is lower in the first period. In subsequent periods, $\hat{r}_{t+i}$ is negative but close to 0 . Thus, the interest payment on the negative position of $N F A$ becomes positive, but is also close to 0 . The inclusion of portfolio choices has no significant impact on the TT effect because the TT effect is mainly linked to the net instead of the gross portfolio position. $(g)$ shows that when $\hat{y}_{t}$ increases, a substantial rise in $\hat{r}_{x}$ combined with $\alpha<0$ leads to a large negative $V A L$ effect. Because the expected future excess returns are 0 in this model, we do not observe any valuation effects in subsequent periods. The dashed line of $(g)$ lies at 0 because the presence of the $V A L$ effect is linked to $\alpha$. When $\alpha=0$, the effect disappears.

Table 2 also reports the sizes of these effects. A one percent increase in $\hat{y}_{t}$ leads to a 0.63 percent increase in the trade balance. In the case without the country asymmetry and portfolio choices, this constitutes the entire adjustment in $N F A$ on impact, so that $\hat{w}$ improves. However, with the presence of the country asymmetry, an external deficit implies a higher interest payment in the home country. So $\hat{w}$ decreases through the negative $T T$ effect, which is $-3.35 \%$. Moreover, if portfolios are optimally chosen, then $\hat{w}$ decreases further as the $V A L$ effect contributes another $8.61 \%$ adjustment downwards.

\subsection{Extending the baseline model}

Non-financial income and alternative country asymmetry To only confine our attention to the impacts of global imbalances on financial integration, in the baseline model, we consider a most parsimonious set of assumptions and deliberately exclude many realistic features for such a model to empirically account for observed country portfolios. In particular, we maintain the assumption that all incomes are capitalizable. In reality, most incomes are non-diversifiable. The role of labour-income hedging can be crucial (Coeurdacier et al., 2010 and Heathcote and Perri, 2013). Besides, in the baseline model, non-zero net portfolios emerge due to the differing patience. Yet the literature finds many other complementary forces at play. For instance, Caballero et al. $(2008,2017)$ argue that the differing financial development of countries is an important 
reason for the phenomena. In what follows, we extend the baseline model in these two aspects. Our questions are: is the hedging of returns on the net external position still important and will the magnitude of portfolio positions and diversification become more plausible when confronting the data?

Consider the same demographic structure and utility function as in the baseline model. However, the budget constraint now reads

$$
\alpha_{1 t+1}^{v}+\alpha_{2 t+1}^{v}=\alpha_{1 t}^{v} r_{1 t}+\alpha_{2 t}^{v} r_{2 t}+y_{l t}+y_{k t}-c_{t}^{v} .
$$

While other notations are familiar, $y_{l t}$ denotes a perishable endowment that the household receives. Besides this income, there are some "trees" in each country which serve as a storage of value and generate an income of $y_{k t}$. Equity assets represent claims on the yield of these trees.

Let us refer to $y_{k t}$ and $y_{l t}$ as the financial and non-financial incomes. Total income $y_{t}$ is assumed to be given by the sum of $y_{k t}, y_{l t}$ and a value loss that is proportional to the stock of trees, $d_{t}=n z_{1 t}$. We use a parameter $\delta$ to describe the share of these incomes in steady state, i.e. with $y=1, y_{k}=\delta-\frac{n \delta}{(r-1)}, y_{l}=1-\delta$ and $d=\frac{n \delta}{(r-1)}$. Following Caballero at al. (2008), we assume $\delta>\delta^{*}$ in the two countries to capture their difference in financial development: the home (foreign) country supplies more (less) asset.

Total incomes follow the same process as in the baseline model. To capture the negative correlation between the financial and non-financial incomes, we follow Bretscher et al. (2016) and Coeurdacier and Gourinchas (2016) in assuming redistributive shocks between the financial and non-financial incomes, $\hat{e}_{t}=\mu_{d} \hat{e}_{t-1}+\varepsilon_{d t}, \hat{e}_{t}^{*}=\mu_{d} \hat{e}_{t-1}^{*}+\varepsilon_{d t}^{*}$. For simplicity, we assume that $\mu_{d}=\mu$ and all shocks have the same variance and zero covariance. ${ }^{5}$

It follows that $N F A$ global imbalances emerge here with the unbalanced financial developments. In particular, the autarky interest rate is relatively higher in the home country, $(1+n \delta) / \beta>\left(1+n \delta^{*}\right) / \beta . r$ lies in the exact middle of the two autarky interest rates at $(1+n \bar{\delta}) / \beta$ with $\bar{\delta}=\left(\delta+\delta^{*}\right) / 2$ denoting the average financial development, which channels net capital from the foreign country $w^{*}=\frac{\left(\bar{\delta}-\delta^{*}\right)}{(1-\bar{\delta})(r-1)}>0$ to the home

\footnotetext{
${ }^{5}$ See Appendix $H$ for a full description of the extended model.
} 
country $w=\frac{(\bar{\delta}-\delta)}{(1-\bar{\delta})(r-1)}<0$. The optimal $\alpha$ can be found to be

$$
\begin{aligned}
\alpha= & -\frac{c c^{*}}{\left(c+c^{*}\right) r} \frac{\operatorname{cov}\left(\Delta y_{k t}, \hat{r}_{x t}\right)}{\operatorname{var}\left(\hat{r}_{x t}\right)}-\frac{c c^{*}}{\left(c+c^{*}\right) r} \frac{\operatorname{cov}\left(\Delta y_{l t}, \hat{r}_{x t}\right)}{\operatorname{var}\left(\hat{r}_{x t}\right)} \\
& -w \frac{\operatorname{cov}\left(\sum_{2 t}^{r n}, \hat{r}_{x t}\right)}{\operatorname{var}\left(\hat{r}_{x t}\right)}+\frac{c c^{*}}{\left(c+c^{*}\right) r} \frac{1-\tau}{1-\beta} \frac{\operatorname{cov}\left(\Delta c_{t}^{n}, \hat{r}_{x t}\right)}{\operatorname{var}\left(\hat{r}_{x t}\right)}
\end{aligned}
$$

where $\Delta y_{k t}$ and $\Delta y_{l t}$ are the relative financial and non-financial incomes and $\Sigma_{2 t}^{r n}=$ $\hat{r}_{2 t}+\frac{\tilde{n}}{r} \sum_{t+1}^{r n}$. Ignoring the last demographic adjustment term, now the hedging of net portfolio returns does not only work with self-hedging but also with a hedging of nonfinancial income.

Model calibration We calibrate the extended model to the U.S. and China's data over $1999-2017 .^{6} 1999$ is selected because not until that year did China start to persistently accumulate positive NFA (Table 3). Prior to the calibration, we discuss two factors that may impact the accuracy of the mapping between the model and the data.

In our model, although asymmetric, the two countries are equal in the sense that, first, the two countries feature the same degree of financial integration. Second, although with opposite signs, the NFAs of the two countries are of the same size. However, the data and the literature, e.g. Lane and Milesi-Ferretti (2007,2017), Gourinchas and Rey (2013), suggest that for different groups of countries, their degrees of financial integration may differ - usually, advanced countries are more financially integrated than emerging and developing countries. They play an unequal role in contributing to the global imbalances - the U.S.' net external debt is much bigger than the credit in China. These two things may be correlated - more financially integrated countries, particularly financial centres, are associated with a larger NFA position. These are broadly true between the U.S. and China, see Table 3.

Besides, the model implies a tight relation between a country's relative capital stock and the size of $N F A$, an underpinning of the hypothesis of global imbalances as a result of the differing $\delta \mathrm{s}$ (Caballero et al., 2008, Gourinchas and Rey, 2013). Specifically, the model implies that $z_{1}-z_{2}=\frac{\delta-\delta^{*}}{(r-1)}=2(1-\bar{\delta}) w^{*}$. That is, to explain a difference of $w=1 \%$ in the model, $z_{1}$ and $z_{2}$ need to differ by (exactly) $2(1-\bar{\delta}) \%$. The data for the U.S. and

\footnotetext{
${ }^{6}$ The data source is detailed in Appendix $I$ Table 4.
} 


\begin{tabular}{cccccccc}
\hline \hline & \multicolumn{3}{c}{ U.S. } & & \multicolumn{3}{c}{ China } \\
\cline { 2 - 3 } \cline { 7 - 8 } Year & $\frac{G A}{G D P}$ & $\frac{G L}{G D P}$ & $\frac{N F A}{G D P}$ & & $\frac{G A}{G D P}$ & $\frac{G L}{G D P}$ & $\frac{N F A}{G D P}$ \\
1987 & 0.32 & 0.36 & -0.04 & & 0.11 & 0.14 & -0.02 \\
1988 & 0.34 & 0.39 & -0.05 & & 0.11 & 0.14 & -0.02 \\
1989 & 0.36 & 0.42 & -0.06 & & 0.10 & 0.13 & -0.03 \\
1990 & 0.36 & 0.41 & -0.06 & & 0.20 & 0.18 & 0.02 \\
1991 & 0.37 & 0.43 & -0.06 & & 0.24 & 0.19 & 0.05 \\
1992 & 0.35 & 0.43 & -0.08 & & 0.17 & 0.20 & -0.03 \\
1993 & 0.40 & 0.46 & -0.06 & & 0.16 & 0.23 & -0.07 \\
1994 & 0.41 & 0.46 & -0.06 & & 0.24 & 0.31 & -0.07 \\
1995 & 0.46 & 0.53 & -0.07 & & 0.22 & 0.30 & -0.09 \\
1996 & 0.50 & 0.57 & -0.07 & & 0.23 & 0.31 & -0.08 \\
1997 & 0.54 & 0.64 & -0.10 & & 0.29 & 0.33 & -0.05 \\
1998 & 0.57 & 0.68 & -0.11 & & 0.32 & 0.33 & -0.01 \\
1999 & 0.64 & 0.72 & -0.09 & & 0.34 & 0.34 & 0.00 \\
2000 & 0.63 & 0.77 & -0.14 & & 0.36 & 0.33 & 0.03 \\
2001 & 0.62 & 0.81 & -0.19 & & 0.37 & 0.34 & 0.03 \\
2002 & 0.63 & 0.83 & -0.20 & & 0.40 & 0.34 & 0.07 \\
2003 & 0.69 & 0.89 & -0.20 & & 0.44 & 0.35 & 0.09 \\
2004 & 0.79 & 0.99 & -0.20 & & 0.48 & 0.35 & 0.14 \\
2005 & 0.95 & 1.12 & -0.17 & & 0.54 & 0.38 & 0.16 \\
2006 & 1.08 & 1.26 & -0.18 & & 0.62 & 0.45 & 0.18 \\
2007 & 1.31 & 1.48 & -0.17 & & 0.69 & 0.45 & 0.24 \\
2008 & 1.32 & 1.59 & -0.27 & & 0.64 & 0.34 & 0.30 \\
2009 & 1.34 & 1.53 & -0.18 & & 0.67 & 0.42 & 0.25 \\
2010 & 1.45 & 1.62 & -0.17 & & 0.68 & 0.44 & 0.24 \\
2011 & 1.43 & 1.72 & -0.29 & & 0.63 & 0.43 & 0.20 \\
2012 & 1.39 & 1.67 & -0.28 & & 0.61 & 0.41 & 0.20 \\
2013 & 1.44 & 1.76 & -0.32 & & 0.62 & 0.43 & 0.19 \\
2014 & 1.42 & 1.82 & -0.40 & & 0.61 & 0.46 & 0.15 \\
2015 & 1.29 & 1.70 & -0.41 & & 0.55 & 0.40 & 0.15 \\
2016 & 1.29 & 1.72 & -0.44 & & 0.58 & 0.41 & 0.17 \\
2017 & 1.43 & 1.82 & -0.40 & & 0.59 & 0.42 & 0.17 \\
\hline & & & & & & \\
\hline
\end{tabular}

Table 3: The portfolio data in the U.S. and China, 1987-2017. Note: GA and GL denote gross assets and liabilities respectively. Data sources include Lane and Milesi-Ferretti's (2007) EWN database and IMF's BOP/IIPS 2019. All measures are in percentage points.

\begin{tabular}{lrr}
\hline \hline & Home country & Foreign country \\
\cline { 2 - 3 } Gross holding of local asset & $\alpha=-0.850$ & $\alpha^{*}=-0.650$ \\
- Self-hedging & -1.866 & -1.866 \\
- Hedging non-financial income & 1.200 & 1.200 \\
- Hedging net external income & -0.110 & 0.091 \\
- Demographic adjustment term & -0.073 & -0.073 \\
\hline
\end{tabular}

Table 4: The extended model: Portfolio holdings and their composition 
China seem to qualitatively corroborate this pattern, i.e. the capital stock to $G D P$ ratio is, on average, higher in the U.S. than in China (Table 5). However, the difference is much larger than $2(1-\bar{\delta})$ times of the observed $N F A$ s. We consider this to be caused by the absence of any trade costs or/and account of imperfect financial integration in the model. As a result, when contrasting the model with data, if we use $\delta$ s to target differing asset supplies in the data, global imbalances will tend to be over-explained; if, instead, the size of NFAs were to be targeted, the country difference in asset supplies and therefore that of portfolio diversification will tend to be under-explained. We will use a wedge analysis in this case, as explained below.

To calibrate the model, we set $n=0.01$ and $\mu=0.91$ (Heathcote and Perri, 2013). Acknowledging the first issue in the above, we make sure that the model matches the U.S. and China's country average counterparts. Specifically, we calibrate $\beta, \delta$ and $\delta^{*}$ to target the two countries' average interest rate $(2.66 \%), N F A / G D P$ ratio $(20 \%)$ and Capital/GDP ratio (3.74) as in the data (the top panel of Table 5). For later use, we divide the whole period into two equal sub-periods: 1999 - 2008 and $2009-2017$ and also use the same strategy to calibrate the model to the two sub-periods' data respectively.

Table 4 decomposes the resulting $\alpha=-0.85$ by Eq.(14). The self-hedging equals -1.866. Thanks to the redistributive shocks, $\operatorname{cov}\left(\Delta y_{l t}, \hat{r}_{x t}\right)$ is negative. The hedging of non-financial income therefore accounts for a long position of the local asset, i.e. 1.200. This keeps most of the local asset within borders by offsetting the effect of the negative self-hedging, in the absence of country asymmetries, to the same degree. A symmetric asset home bias would emerge as emphasised by the existing symmetric portfolio models. The demographic adjustment term is given by -0.073 in the two countries.

Our point is that, the differing $\delta$ s open non-zero net external positions and hence again create the needs to hedge against the associated risks. As in the baseline model, the hedging has an opposite sign in the two countries. Should the country concerned be a creditor country, the hedging would be positive and reinforce the effect of the hedging of non-financial income in leading to a more home-biased portfolio. Otherwise, the hedging would be negative and reinforce the effect of the basic self-hedging in leading to a "more diversified" portfolio. Compared to a symmetric model, this implies that the preferences for the local asset in the two countries are bent to different degrees and the asset home bias exhibits a heterogeneity that corroborates the data (Coeurdacier and Rey, 2013). 


\begin{tabular}{|c|c|c|c|c|c|c|}
\hline DATA & $\mathrm{r}$ & GA/GDP & GL/GDP & NFA/GDP & Capital/GDP & $\begin{array}{l}\text { Locally-held } \\
\text { domestic } \\
\text { asset share }\end{array}$ \\
\hline \multicolumn{7}{|c|}{ The whole period: $99-17$} \\
\hline U.S. & 2.98 & 1.11 & 1.36 & -0.25 & 4.20 & 0.68 \\
\hline China & 2.33 & 0.55 & 0.39 & 0.16 & 3.29 & 0.88 \\
\hline Average & 2.66 & 0.83 & 0.88 & $0.20^{*}$ & 3.74 & 0.77 \\
\hline \multicolumn{7}{|c|}{ Sub-period 1: 99-08 } \\
\hline U.S. & 4.04 & 0.86 & 1.05 & -0.18 & 3.76 & 0.72 \\
\hline China & 2.18 & 0.49 & 0.37 & 0.12 & 2.97 & 0.88 \\
\hline Average & 3.11 & 0.68 & 0.71 & 0.15 & 3.37 & 0.79 \\
\hline \multicolumn{7}{|c|}{ Sub-period 2: 09-17 } \\
\hline U.S. & 1.80 & 1.39 & 1.71 & -0.32 & 4.68 & 0.64 \\
\hline China & 2.51 & 0.62 & 0.42 & 0.19 & 3.65 & 0.88 \\
\hline Average & 2.16 & 1.00 & 1.06 & 0.26 & 4.16 & 0.74 \\
\hline \multicolumn{7}{|c|}{ Between 2 sub-periods } \\
\hline U.S. & -2.23 & 0.52 & 0.66 & -0.14 & 0.92 & -0.08 \\
\hline China & 0.33 & 0.13 & 0.06 & 0.07 & 0.67 & 0.00 \\
\hline Average & -0.95 & 0.32 & 0.36 & 0.10 & 0.80 & -0.05 \\
\hline \multicolumn{7}{|l|}{ MODEL } \\
\hline \multicolumn{7}{|c|}{ The whole period: $99-17$} \\
\hline Home & 2.66 & 0.65 & 0.85 & -0.20 & 3.93 & 0.78 \\
\hline Foreign & 2.66 & 0.85 & 0.65 & 0.20 & 3.56 & 0.82 \\
\hline \multirow{2}{*}{\multicolumn{7}{|c|}{$\begin{array}{l}\text { Average } 2.00 \\
\text { Sub-period 1: } 99-08\end{array}$}} \\
\hline & & & & & & \\
\hline Home & 3.11 & 0.52 & 0.67 & -0.15 & 3.51 & 0.81 \\
\hline Foreign & 3.11 & 0.67 & 0.52 & 0.15 & 3.24 & 0.84 \\
\hline Average & 3.11 & 0.60 & 0.60 & 0.15 & 3.38 & 0.82 \\
\hline \multicolumn{7}{|c|}{ Sub-period 2: 09-17 } \\
\hline Home & 2.15 & 0.86 & 1.12 & -0.26 & 4.39 & 0.74 \\
\hline Foreign & 2.15 & 1.12 & 0.86 & 0.26 & 3.92 & 0.78 \\
\hline Average & 2.15 & 0.99 & 0.99 & 0.26 & 4.16 & 0.76 \\
\hline \multicolumn{7}{|c|}{ Between 2 sub-periods } \\
\hline Home & -0.96 & 0.34 & 0.45 & -0.11 & 0.88 & -0.06 \\
\hline Foreign & -0.96 & 0.45 & 0.34 & 0.11 & 0.68 & -0.06 \\
\hline Average & -0.96 & 0.40 & 0.40 & 0.11 & 0.78 & -0.06 \\
\hline
\end{tabular}

Table 5: The portfolio data vs extended model. Note: Except for Capital/GDP, all measures are in percentage points. * Because NFAs have opposite signs across the two countries, the average of their absolute values is reported.

\begin{tabular}{|c|c|c|c|c|c|c|}
\hline \multirow[b]{3}{*}{ Home } & \multirow[b]{2}{*}{ Wedge } & \multicolumn{2}{|c|}{ Data } & \multicolumn{3}{|c|}{ Model: $09-17$} \\
\hline & & $99-08$ & 09-17 & (i) & (ii) & (iii) \\
\hline & 1.4558 & 0.72 & 0.64 & 0.70 & 0.70 & 0.63 \\
\hline Foreign & 0.7659 & 0.88 & 0.88 & 0.88 & 0.88 & 0.83 \\
\hline
\end{tabular}

Table 6: The data vs model predictions: portfolio bias between periods. 
Table 5 compares the implied portfolios to the data. In the last column of the table, we also report the locally-held domestic asset share as a measure of the lack of portfolio diversification (or portfolio bias) in the two countries (French and Poterba, 1991, Cooper and Kaplanis, 1994, Tesar and Werner, 1995, etc.) In general, the model accounts fairly well for the observed data, including the unbalanced $N F A$ s across countries, the lack of portfolio diversification in both countries, and China's portfolio being more biased toward its home asset than that of the U.S.. The remaining mismatch between the model and the data can mostly be attributed to the two factors that we discussed before. In particular, in the model, the two countries have the same $N F A$ size, so the $N F A$ in the home (foreign) country is smaller (larger) than that in the U.S. (China); both countries are equally financially integrated, the financial integration index being both 1.5 as compared to 2.47 (U.S.) and 0.94 (China) in the data, which tends to overstate (understate) the portfolio bias in the more (less) financially integrated country, i.e. U.S. (China); because the model targets the average $N F A$ s, this, as expected, implies a smaller difference in $\delta$ s and therefore that in capital stocks. This also tends to yield a relatively smaller gap between the two countries' portfolio bias as compared to the data.

As such, we follow the literature in using a portfolio wedge to represent the factors that are important for the determination of portfolio choices while unidentified in the model when matching the data (e.g. Gourinchas and Jeanne, 2013, Steinberg, 2018, etc.) In particular, we use the following strategy to understand how the change in the globalimbalances-relevant country asymmetry helps explain the changes in countries' net and gross portfolios: First, we calibrate the model to the data of the 1st sub-period. In the process, we use country-specific portfolio wedges to ensure that the portfolio bias in each country matches that of the data. Second, keeping these portfolio wedges fixed, we recalibrate the model to the data of the 2 nd sub-period, compute the portfolios and their bias, and compare the data with model predictions. Depending on the parameters that are allowed to adjust when re-calibrating the model, we distinguish the following three cases: In case (i), only $\delta^{*}$ is allowed to fall to match the rising $N F A$ s. To interpret this, the diverging global imbalances are only driven by the financial underdevelopment of the emerging/developing country, a hypothesis of global saving glut. Given that it is still an open question whether the $N F A$ s' diverging trend is due to the global saving glut or a (U.S.) domestic investment drought (a decline in $1-\delta$ here) (Kehoe et al. 2018), in case 
(ii), we allow both $\delta$ and $\delta^{*}$ to adjust. Lastly, in case (iii), we follow the literature in interpreting both the expanding $N F A$ s and the declining $r$ as the integral facets of the global imbalances (Bernanke, 2005, Gourinchas and Rey, 2013, etc.). To do so, we allow both $\beta$ and $\delta$ s to adjust when matching the data of the 2 nd sub-period.

Table 6 reports the results of this exercise and the associated portfolio wedges. In both periods, the portfolios in China exhibit a higher degree of home bias than those in the U.S.. The bias degree declines over time in the U.S. while this trend is not obvious in China. The model seems to capture much of these patterns, in all three cases that are mentioned above. In particular, as expected, the model predicts that the degree of home bias falls at a relatively faster rate in the home advanced country than in the foreign emerging/developing country (Coeurdacier and Rey, 2013).

Additional remarks The model predictions and the data are broadly consistent. Through these experiments, we emphasise that, even with a simple structure, the model produces international portfolios of an empirically relevant magnitude for the countries with large unbalanced NFA positions. The presence of the new hedging of $N F A$ returns is key. While we only consider the extension to non-diversifiable incomes, we can easily enrich this framework with other features such as alternative country asymmetry, production, heterogeneous goods, bond assets, etc., in order to bring the predicted portfolios closer to the data. In any event, we expect the hedging of $N F A$ returns to remain. The reason, as explained, is related to the unbalanced $N F A$ s' impact on relative national consumptions. In general, global imbalances open a gap between the GNP and GDP of the country. This exposes households to a new source of income risks to be hedged by holding portfolios. As a complementary force to the other hedging of GDP components in shaping $\alpha$, this hedging of NFA returns will not disappear as long as the $N F A$ s are unbalanced.

A more sophisticated model may involve the variable dynamics that differ from (or/and are even opposite to) those in our baseline model. This may not necessarily change the hedging property of the assets and the property of portfolio components. As an example, Coeurdacier et al. (2010), Heathcote and Perri (2013), etc., consider the portfolio choices in a (symmetric) model with production, capital accumulation, goods home bias and exchange rate adjustment à la Backus et al., (1994) (BKK henceforth). In such a framework, the investment will be so elastic that after a rise in domestic $T F P$, it reduces 
(instead of raises) the local asset's dividends as well as the relative return $\hat{r}_{x t}$. So when labour income is high (in response to a positive domestic TFP shock), the domestic asset pays out less. The hedging of labour is positive. By including the redistributive shocks, the above extended model is isomorphic to the BKK model in the sense that the $\hat{r}_{x t}$ 's dynamics resemble that of the BKK model, e.g. Heathcote and Perri (2013). The implications on portfolio choices are therefore analogous. In particular, extending the baseline model to a BKK environment will not alter the $\alpha$ [2]'s sign. The reason for this is simple. In the baseline model, because both asset returns are more (positively) responsive to the domestic shocks, $\operatorname{cov}\left(\hat{r}_{2 t}, \hat{r}_{x t}\right)$ and $\operatorname{cov}\left(\hat{r}_{1 t}, \hat{r}_{x t}^{*}\right)$ are negative. The sign of $\alpha[2]=-w \frac{\operatorname{cov}\left(\hat{r}_{2 t}, \hat{r}_{x t}\right)}{\operatorname{var}\left(\hat{r}_{x t}\right)}\left(\alpha^{*}[2]=-w^{*} \frac{\operatorname{cov}\left(\hat{r}_{1 t}, \hat{r}_{x t}^{*}\right)}{\operatorname{var}\left(\hat{r}_{x t}^{*}\right)}\right)$ is determined by that of the country's NFA, which is negative (positive). In the extended model or/and the BKK model, both asset returns are more (positively) responsive to the overseas shocks, i.e. $\hat{r}_{x t}\left(\hat{r}_{x t}^{*}\right)$ declines while $\hat{r}_{2 t}\left(\hat{r}_{1 t}\right)$ rises in response to the home (foreign) income windfalls. This also implies negative $\operatorname{cov}\left(\hat{r}_{2 t}, \hat{r}_{x t}\right)$ and $\operatorname{cov}\left(\hat{r}_{1 t}, \hat{r}_{x t}^{*}\right)$. So, as previously, the sign of $\alpha[2]$ relies on that of $N F A$ s and is opposite across countries.

Appendix $H$ extends our model by including an additional international bond (Coeurdacier et al., 2010, Devereux et al., 2014, Coeurdacier and Gourinchas, 2016). It follows that, as long as global imbalances are present, the hedging of $N F A$ returns will also remain (except that the hedging is conditional as in the symmetric set-ups such as Coeurdacier and Gourinchas, 2016).

Although our paper takes the country asymmetry as static so that the steady-state NFA positions are stationary, there is no reason for this to be true in reality, particularly in the light of the continuing deterioration of the U.S. net debtor position (Table 3). There is little sign of the global imbalances being overturned in the short term. In fact, some data projections point to exactly the opposite (IMF, 2017). In the case of even more deepening global imbalances, the current model predicts a growing role of the motive to hedge against NFA returns in shaping the international portfolios and financial markets in the time to come. 


\section{Conclusion}

Accelerating financial globalization is inextricably intertwined with diverging $N F A$ global imbalances, which requires a joint analysis. We studied their relationship by examining the interaction between the two most important optimizing tools in a global economy: current account smoothing of consumption over time and country portfolios across states.

The hedging of net portfolio returns is highlighted as the key link through which persistent unbalanced NFA positions affect gross portfolio choices. Different from the other hedging terms of country portfolios that are found to be symmetric in the existing literature, the hedging of net portfolio returns is asymmetric. Its sign depends on the country's status in international payments, negative in the debt country while positive in the credit country, which explains why gross portfolio positions differ along the financial integration in these countries. Moreover, the new hedging complements the other hedging in shaping the international portfolio diversification, in particular as a potential explanation for the observed heterogeneity in the portfolio bias across countries. The model captures both the trade effect and the valuation effects that complete the country's external adjustment. With the development of financial globalization, the cross-border wealth transfer in the form of portfolio valuation effects may become more and more frequent and important, asking for a further exploration of its impacts including the welfare implications for various countries within a model of both net and gross country portfolios.

The model is fully optimizing and micro-founded. As a bridge between the literature on global imbalances and that on portfolio choices, it allows for meaningful extensions along these two dimensions. For the former, a different story of global imbalances than those adopted here can be explored. The hedging of net portfolio returns, however, is expected to persist. For the latter, as mentioned, future work may involve the incorporation of additional hedging motives, hedging tools, and realistic frictions into the analysis. While the paper focuses on the steady-state portfolios, the investigation of the portfolio dynamics, i.e. capital flows, within the asymmetric framework can follow. It would also be very interesting to extend the model to study the related open economy policy issues under global imbalances. 


\section{REFERENCES}

Angeletos, George-Marios \& Vasia Panousi, 2011. Financial Integration, Entrepreneurial Risk and Global Dynamics. Journal of Economic Theory 146.3 (2011): 863-896.

Attanasio, Orazio \& Kitao Sagiri \& Giovanni L. Violante, 2006. Quantifying the Effects of the Demographic Transition in Developing Economies. B.E.J. Macroeconomics (Advances) 6 (1): Pages 1-44, April.

Backus, David K. \& Partrick J. Kehoe \& Finn E. Kydland, 1994. Dynamics of the Trade Balance and the Terms of Trade: The J-Curve? American Economic Review, 84 (1): 84-103.

Banerjee, Abhijit \& Meng, Xin \& Porzio, Tommaso \& Nancy Qian, 2014. Fertility Change and Household Savings in China: Evidence from a General Equilibrium Model and Micro Data, Yale University working paper.

Bernanke, Ben S., 2005. The Global Saving Glut and the U.S. Current Account Deficit, Speech 77, Board of Governors of the Federal Reserve System (U.S.)

Bhagwati, Jagdish., 1958, Immiserizing Growth: A Geometrical Note, The Review of Economic Studies, vol. 25, no. 3, 1958, pp. 201-205.

Blanchard, Olivier \& Giavazzi, Francesco \& Sa, Filipa, 2005. International Investors, the U.S. Current Account, and the Dollar, Brookings Papers on Economic Activity, Economic Studies Program, The Brookings Institution, vol. 36(1), pages 1-66.

Bodenstein, Martin, 2011. Closing Large Open Economy Models, Journal of International Economics, Elsevier, vol. 84(2), pages 160-177, July.

Bretscher, Lorenzo \& Julliard, Christian \& Rosa, Carlo, 2016. Human Capital and International Portfolio Diversification: A Reappraisal, Journal of International Economics, Elsevier, vol. 99, supplement 1, pages S78-96, March.

Buiter, Willem H, 1981. Time Preference and International Lending and Borrowing in an Overlapping-Generations Model, Journal of Political Economy, University of Chicago Press, vol. 89(4), pages 769-97, August.

Caballero, R. \& Farhi E., \& P.-O. Gourinchas, 2008. An Equilibrium Model of Global Imbalances and low Interest Rates, American Economic Review, 98(1), 358-93.

Caballero, R. \& Farhi E., \& P.-O. Gourinchas, 2017. The Safe Assets Shortage Conundrum, Journal of Economic Perspectives, (Summer): 29-46.

Cavallo, Michele \& Ghironi, Fabio, 2002. Net Foreign Assets and the Exchange Rate: Redux Revived, Journal of Monetary Economics, 49, July 2002, Pages 1057-97.

Chamon, Marcos D. \& Prasad, Eswar S., 2010. Why Are Saving Rates of Urban Households in China Rising? American Economic Journal: Macroeconomics, 2(1), 93-130.

Coeurdacier, Nicolas \& P.-O. Gourinchas, 2016. When Bonds Matter: Home Bias in Goods and Assets, Journal of Monetary Economics, 82, 119-137.

Coeurdacier, Nicolas \& Guibaud, Stéphane \& Jin, Keyu, 2015, Credit Constraints and Growth in a Global Economy, American Economic Review, Vol. 105, No. 9 (Sep., 2015), pages 2838-81.

Coeurdacier, Nicolas \& Robert Kollmann \& Phillipe Martin, 2007. International Portfolios with Supply, Demand, and Redistributive Shocks. In National Bureau of Economic Research (NBER) International Seminar in Macroeconomics. Vol. 4, edited by Richard Clarica and Francesco Giavazzi, 231-81. Chicago: University of Chicago Press.

Coeurdacier, Nicolas \& Robert Kollmann \& Phillipe Martin, 2010. International Portfolios, Capital Accumulation and Foreign Assets Dynamics, Journal of International Economics, Elsevier, vol. 80(1), pages 100-112, January.

Coeurdacier, Nicolas \& Rey, Hélène, 2012. Home Bias in Open Economy Financial Macroeconomics, Journal of Economic Literature, American Economic Association, vol. 51(1), pages 63-115, March.

Cooper, I.A. \& Kaplanis, E., 1994. Home Bias in Equity Portfolios, Inflation Hedging, and International Capital Market Equilibrium. Review of Financial Studies, 7, 45-60. 
Curtis, Chadwick C. \& Lugauer, Steven \& Mark, Nelson, 2015. Demographic Patterns and Household Saving in China, American Economic Journal: Macroeconomics, 7(2): 58-94.

Devereux, Michael. \& Sutherland, Alan, 2009. A Portfolio Model of Capital Flows to Emerging Markets, Journal of Development Economics, 89, 181-193.

Devereux, Michael. \& Sutherland, Alan, 2010a. Valuation Effects and the Dynamics of Net External Assets, Journal of International Economics, Elsevier, vol. 80(1), pages 129-143, January.

Devereux, Michael. \& Sutherland, Alan, 2010b. Country Portfolio Dynamics, Journal of Economic Dynamics \& Control, vol. 34, 1325-1342.

Devereux, Michael. \& Sutherland, Alan, 2011. Country Portfolios in Open Economy Macro Models, Journal of the European Economic Association, 9, 337-369.

Devereux, Michael. \& Senay, Ozge \& Sutherland, Alan, 2014. Nominal Stability and Financial Globalization, Journal of Money, Credit and Banking, 46, 921-959.

Engel, C. \& J. Rogers, 2006. The U.S. Current Account Deficit and the Expected Share of World Output, Journal of Monetary Economics, Vol. 53, No. 5, pp. 1063-193.

Eugeni, Sara, 2015, An OLG Model of Global Imbalances, Journal of International Economics, Volume 95, Issue 1, January 2015, Pages 83-97.

Evans, Martin \& Viktoria, Hnatkovska, 2012. A Method for Solving General Equilibrium Models with Incomplete Markets and Many Financial Assets, Journal of Economic Dynamics and Control, Vol. 36, Issue 12, 1909-30

Ferrero, Andrea \& Mark Gertler \& Lars E. O. Svensson, 2007. Current Account Dynamics and Monetary Policy, International Dimensions of Monetary Policy, University of Chicago Press, Edited by Jordi Galí and Mark J. Gertler: pp. 199-243.

French, Kenneth R., \& James M. Poterba, 1991, Investor Diversification and International Equity Markets, American Economic Review, 81(2), 222-26.

Fogli, A. \& Perri, F., 2015. Macroeconomic Volatility and External Imbalances, Journal of Monetary Economics, Volume 69, January 2015, Pages 1-15.

Ghironi, Fabio, 2006. Macroeconomic Interdependence under Incomplete Markets, Journal of International Economics, Volume 70, December 2006, Pages 428-450.

Ghironi, Fabio \& Lee, Jaewoo \& Rebucci, Alessandro, 2015. The Valuation Channel of External Adjustment, Journal of International Money and Finance 57 (October 2015): 86-114.

Gourinchas, Pierre-Olivier \& Jeanne, Olivier, 2013. Capital Flows to Developing countries: The Allocation Puzzle, The Review of Economic Studies, Vol. 80, No. 4 (285) (October 2013), pp. 1484-1515.

Gourinchas, Pierre-Olivier \& Rey, Hélène, 2007. International Financial Adjustment, Journal of Political Economy, University of Chicago Press, vol. 115(4), pages 665-703, 08.

Gourinchas, Pierre-Olivier \& Rey, Hélène, 2013. External Adjustment, Global Imbalances and Valuation Effects, Handbook of International Economics, 585-640, Gopinath, Helpman and Rogoff eds.

Heathcote, Jonathan \& Perri, Fabrizio, 2013, The International Diversification Puzzle Is Not as Bad as You Think, Journal of Political Economy, vol. 121, no. 6, 2013, pp. 1108-1159.

Henriksen, Espen R. 2005. A Demographic Explanation of U.S. and Japanese Current Account Behavior. Manuscript, Univ. Oslo.

IMF, 2017, 2017 External Sector Report, IMF policy paper, Press release No. 17/331, July 28,2017

Jin, Keyu, 2012. Industrial Structure and Capital Flows, American Economic Review, 102(5), 2111-2146.

Kehoe, T.J., \& Ruhl, K.J. \& Steinberg, J.B., 2018. Global Imbalances and Structural Changes in the United States, Journal of Political Economy, 126, 761-796.

Kollmann, Robert, 2006. International Portfolio Equilibrium and the Current Account, CEPR Discussion Papers 5512, C.E.P.R. Discussion Papers. 
Lane, Philip R. \& Milesi-Ferretti, Gian Maria, 2007, The External Wealth of Nations Mark II: Revised and Extended Estimates of Foreign Assets and Liabilities, 1970-2004, Journal of International Economics, 73, November, 223-250.

Lane, Philip R. \& Milesi-Ferretti, Gian Maria, 2017, International Financial Integration in the Aftermath of the Global Financial Crisis, IMF Working Paper, No. 17/115, May 2017.

Lewis, Karen K., 1999, Trying to Explain Home Bias in Equities and Consumption, Journal of Economic Literature, 37(2), 571-608.

Lucas, Robert E, Jr., 1982. Interest Rates and Currency Prices in a Two-country World, Journal of Monetary Economics, Elsevier, vol. 10(3), pages 335-359.

Mendoza, E. \& V. Quandrini \& V. Rios Rull, 2009. Financial Integration, Financial Deepness, and Global Imbalances, Journal of Political Economy, 117(3), 371-416.

Mukherjee, R., 2015. Institutions, corporate governance and capital flows. Journal of International Economics96 (2), 338-359.

Obstfeld, Maurico, 2004. External Adjustment, Review of World Economics (Weltwirtschaftliches Archiv), Springer, vol. 140(4), pages 541-568, December.

Obstfeld, Maurice \& Rogoff, Kenneth S., 1996. Foundations of International Macroeconomics, MIT Press Books, The MIT Press, edition 1, volume 1, number 0262150476, December.

Rabitsch, Katrin \& Serhiy, Stepanshuk \& Viktor, Tsyrennikov, 2015. International Portfolios: A Comparison of Solution Methods, Journal of International Economics, Vol. 97, 404-422

Schmitt-Grohe, S., Uribe, M., 2003. Closing Small Open Economy Models. Journal of International Economics, 61, 163-185

Sercu, Piet \& Rosanne Vanpee, 2007, Home bias in International Equity Portfolios: A Review, Catholic University Leuven Department of Accountancy, Finance and Insurance Working Paper 0710

Smets, Frank \& Wouters, Rafael, 2007. Shocks and Frictions in US Business Cycles: A Bayesian DSGE Approach, American Economic Review, Vol. 97, No. 3, June, 586-606.

Song, M. \& Storesletten K. \& Zilibotti F., 2011. Growing like China. American Economic Review, Vol. 101(1), 196-233.

Steinberg, Joseph, 2018. International Portfolio Diversification and theh Structure of Global Production, Review of Economic Dynamics, 29, 195-215

Stepanchuk, Serhiy \& Viktor, Tsyrennikov, 2015. Portfolio and Welfare Consequences of Debt Market Dominance, Journal of Monetary Economics, Vol. 74, pages 89-101

Tesar, L. L., \& Werner, I. M. 1995. Home Bias and High Turnover. Journal of International Money and Finance, 14(4), 467-492.

Tille, Cédric \& van Wincoop, Eric, 2010. International Capital Flows, Journal of International Economics, Elsevier, vol. 80(2), pages 157-175, March.

Wei, Shang-Jin, \& Xiaobo Zhang, 2011, The Competitive Saving Motive: Evidence from Rising Sex Ratios and Savings Rates in China, Journal of Political Economy, 199(3): 511-64.

Weil, Philippe, 1989. Overlapping Families of Infinitely-lived Agents, Journal of Public Economics, Elsevier, vol. 38(2), pages 183-198, March. 